\title{
GPS and Sensor Based Technologies in Variable Rate Fertilizer Application
}

\author{
S. Sai Mohan ${ }^{1 *}$, A. Ajay ${ }^{2}$ and Jayan, P.R. ${ }^{3}$ \\ ${ }^{1,3}$ Department of Farm Machinery and Power Engineering, Kelappaji College of Agricultural Engineering and Technology, Kerala \\ Agricultural University, Thrissur, India \\ ${ }^{2}$ Department of Farm Machinery and Power Engineering, Dr. NTR College of Agricultural Engineering, ANGRAU, Bapatla, \\ Guntur, India
}

"Corresponding author: samalasaimohan@gmail.com (ORCID ID: 0000-0002-4899-8864)

Paper No. 879

Received: 02-01-2021

Revised: 23-02-2021

Accepted: 05-03-2021

\begin{abstract}
With an average consumption of $165.8 \mathrm{~kg}$ per hectare, India stands as the third-largest producer and consumer of fertilizer in the world. Farmers practice traditional methods to apply fertilizers uniformly throughout the field. This uniform and constant rate application of fertilizer is inefficient and mostly leads to over-fertilizing certain areas and at the same time, under-fertilizing others, not meeting the actual nutrient demand. Variable-rate fertilizer application (VRFA) is the process of applying various rates of crop nutrients by synchronizing existing machinery with mechatronics according to the variability within any agricultural field. One such effort are to be made to develop VRFA systems to meet the soil and plant needs. A variable rate fertilizer application (VRFA) system based on a digital map was developed in Kharagpur and achieved an appreciable target application rate at selected grid points (Chandel et al., 2016). The system was effective, accurate and showed quick response to target application rates with a negligible time lag. The coefficient of variation at all the outlets was in the range of 11.7-15.0 percent. The system was able to meet the target fertilizer application rate with a variation of up to 15 percent for a grid resolution of $8 \times 8 \mathrm{~m}$. Another VRFA system was developed for controlling the amount of fertilizer that works by measuring the NDVI of crops using an optical sensor (Zhang et al. 2014). This type of VRFA system does not use prescription maps but relies on sensors to provide real-time crop detection. The coefficient of variation was ranging from 0.35 to 2.67 percent and elapsed a response time of less than $0.875 \mathrm{~s}$. The system helps in maintaining desired application rate by making real-time adjustments with on-the-go monitoring. It is revealed that the use of VRFA system helped to improve input use efficiency and decrease the negative effect on the environment. Thus, it is a promising technology through which the performance of a unit area could be tracked, mapped and analyzed. Also, the farmer will be able to know the exact production of each part of the field.
\end{abstract}
Highlights
( Basic GPS and sensor-based VRT systems are discussed.
0 Working of VRT systems was depicted with schematic representation and flowcharts.
( Results from various research works were summarized.

Keywords: Variable rate application, digital map, optical sensor, NDVI

Excessive use of chemical fertilizers is a very serious problem in agriculture at present. Excess nitrogen used in crop fertilization can contribute to the release of greenhouse gases such as carbon dioxide and nitrous oxide into the atmosphere. Excessive use of fertilizers can reduce the natural replenishing ability of soil and can change the chemical nature

How to cite this article: Mohan, S.S., Ajay, A. and Jayan, P.R. 2021. GPS and Sensor Based Technologies in Variable Rate Fertilizer Application. IJAEB, 14(1): 21-27.

Source of Support: None; Conflict of Interest: None 
of the soil, making it less fertile. It not only leads to soil compaction and acidification and causes the fertilizer utilization rate of soil to drop down to extremely low and creates pollution of groundwater. Root burning was also a serious issue.

Macro-nutrients availability in the soil is not the same throughout the field and varies from location to location. Recent research indicates that there is a high variability of soil nutrients even in a small area of the field. The constant rate of fertilizer application is inefficient and leads to over-fertilizing certain regions and under-fertilizing others, not meeting the actual nutrient demand. Over-application of chemical fertilizer to plants may cause the leaves to turn yellow or brown, damaging the plant and reducing crop yield. This condition is known as chemical leaf scorch. Leaf scorch can cause the leaves of the plant to wither and may cause the plant to die. The over-use of chemical fertilizers can lead to soil acidification because of a decrease in organic matter in the soil. Nitrogen applied to fields in large amounts over time damages topsoil, resulting in reduced crop yields. Clay soils have an ability to buffer the effects of excess chemical fertilization, but sandy soils lack this ability and prone to soil acidification more than clay soils.

Variable-rate technology combines a variable-rate (VR) control system with application equipment to apply inputs at a precise time or location to achieve site-specific application rates of inputs. A complement of components, such as a DGPS receiver, computer, and VRA software and controller, are integrated to make VRT work.

\section{Effects of irregular fertilizer application}

Excessive use of chemical fertilizers is a very serious problem in agriculture at present. Excess nitrogen used in crop fertilization can contribute to the release of greenhouse gases such as carbon dioxide and nitrous oxide into the atmosphere. Excessive use of fertilizers can reduce the natural replenishing ability of soil and can change the chemical nature of soil, making it less fertile. It not only leads to soil compaction and acidification and causes the fertilizer utilization rate of soil to drop down to extremely low and creates pollution of groundwater. Root burning was also a serious issue.

Over-application of chemical fertilizer to plants may cause the leaves to turn yellow or brown, damaging the plant and reducing crop yield. This condition is known as chemical leaf scorch. Leaf scorch can cause the leaves of the plant to wither and may cause the plant to die. The over-use of chemical fertilizers can lead to soil acidification because of a decrease in organic matter in the soil. Nitrogen applied to fields in large amounts over time damages topsoil, resulting in reduced crop yields. Clay soils have the ability to buffer the effects of excess chemical fertilization, but sandy soils lack this ability and prone to soil acidification more than clay soils.

\section{Approaches to site-specific farming}

In precision agriculture (PA), three basic methods of implementing site-specific variable rate fertilizer application (VRFA) within a field include:

- By controlling the speed of rotary valve

- GPS with prescription map

- Optical sensor

- Real-time spot application using GPS

Manual control can also be used to vary the application rates with the operator responsible for changing the rates on the controller during operation.

- By changing the active length and speed of the fluted roller

- By changing the opening of dosing plates

\section{REVIEW OF LITERATURE}

\section{GPS with prescription map approach}

In the map-based approach, a prescription map is generated based on soil analyses or other information and then used by the VRT to control the desired application rate within each zone.

The tractor-mounted VRFA system consisted of :

1. Differential global positioning system (DGPS)

2. Micro-processer

3. Micro-controller

4. DC motor

5. Fluted roller metering mechanism

For variable-rate fertilizer application in a particular field, the map-based method includes the following steps: 
- Perform systematic soil sampling (and lab analysis) for the field;

- Generate site-specific maps of the soil nutrient properties of interest;

- Use some algorithm to develop a site-specific fertilizer application map; and

- Use the application map to control a variablerate fertilizer applicator.

A positioning system is used during the sampling and application steps to continuously record vehicle location in the field. Differentially-corrected global positioning system (DGPS) receivers are the most commonly used positioning devices.

\section{Advantages of Map-Based Variable-Rate Application}

1. Systems are already available for most crop production inputs.

2. The user has a database that can be useful for a number of management-related activities.

3. The user can employ multiple sources of information in the process of formulating a variable-rate application plan.

4. The user has significant control regarding the function of such systems because of the involvement in application rate planning.

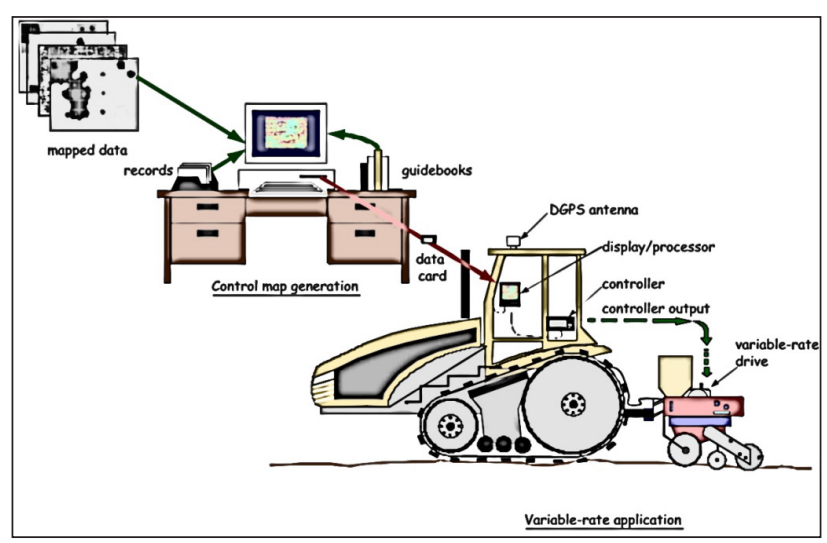

Fig. 1: A map-based system for varying crop input application rates

Chandel et al. (2016) developed a digital mapbased site-specific granular fertilizer application system for applying different rates of crop inputs. It consisted of a differential global positioning system (DGPS), microprocessor, micro-controller, DC motor actuator, power supply, threaded screw arrangement, and fluted roller metering mechanism.
Soil nutrient availability and application maps for targeted yield were also developed. DGPS was used for real-time identification of grids. Based on the microcontroller algorithm, application rates were varied by changing the feed roller exposure length. The observed fertilizer application rate was 5 and $300 \mathrm{~kg} \mathrm{ha}^{-1}$ for exposure lengths of 0 and $44 \mathrm{~mm}$ respectively. The results indicate that the fertilizer application rate changes according to the prescribed application rate at the identified grid with a coefficient of variation of 11.7-15 percent. The fertilizer application accuracy ranged from 89.3 to 98.1 percent at various discharge rates.
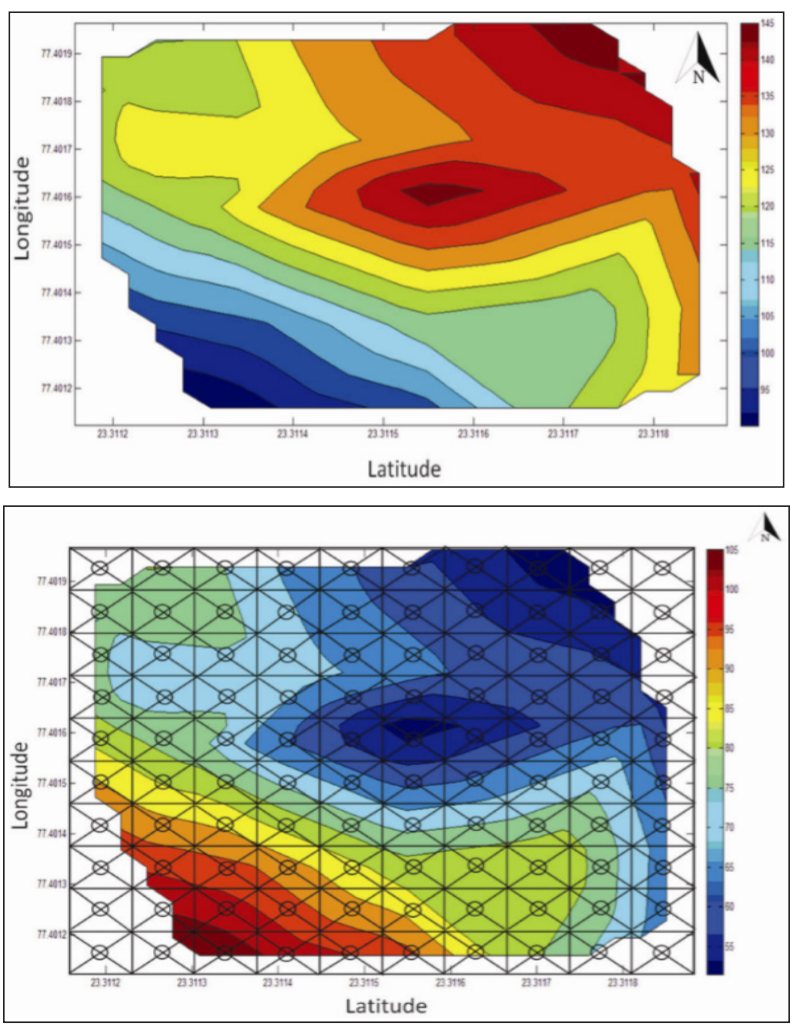

Fig. 2: Nitrogen availability map developed using MATLAB

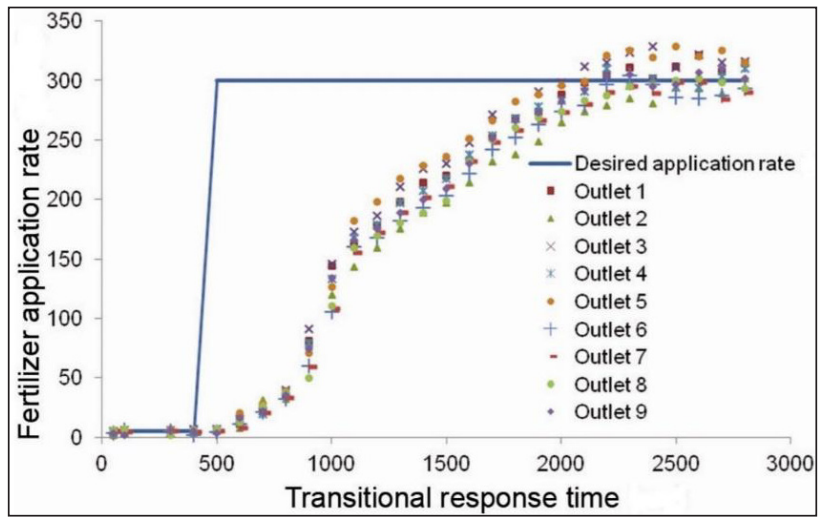

Fig. 3 Variation of transitional response time w.r.t fertilizer application rate 
Kim et al. (2008) developed a variable-rate granule applicator with a $10 \mathrm{~m}$ long boom. This system consisted of a soil property map of $10 \times 10 \mathrm{~m}$ grid size. The pneumatic applicator was equipped with simple blow heads and a metering system. The reported CV values, regardless of the working speed, ranged from $2.9 \%$ to $15.3 \%$ and $11.2 \%$ to $13.1 \%$ in the longitudinal and transverse directions, respectively. Tola et al. (2008) modified a mechanical fertilizer application system for the automatic setting of target fertilizer application rate. The system could maintain a uniform application rate by performing real-time adjustments with an on-the-go monitoring application.

Ning et al. (2015) developed a variable rate fertilization system with adjustable active feedroll length. The system consisted of a seed drill, actuator, a low-cost support decision subsystem, and corresponding software. A SpatiaLite database was employed to solve the spatial location search and spatial data query. Experiments were conducted to evaluate the fertilization uniformity and dynamic response time. The coefficient of variation in five different active feed-roll lengths was $8.4 \%$ which reflects a good uniformity. The dynamic response times for the adjustment of variable-rate fertilization system from $204 \mathrm{~kg} \mathrm{~h}^{-1} \mathrm{~m}^{-2}$ to $319 \mathrm{~kg} \mathrm{~h}^{-1} \mathrm{~m}^{-2}$ and 319 $\mathrm{kg} \mathrm{h}^{-1} \mathrm{~m}^{-2}$ to $204 \mathrm{~kg} \mathrm{~h}^{-1} \mathrm{~m}^{-2}$ are about $4.2 \mathrm{~s}$.

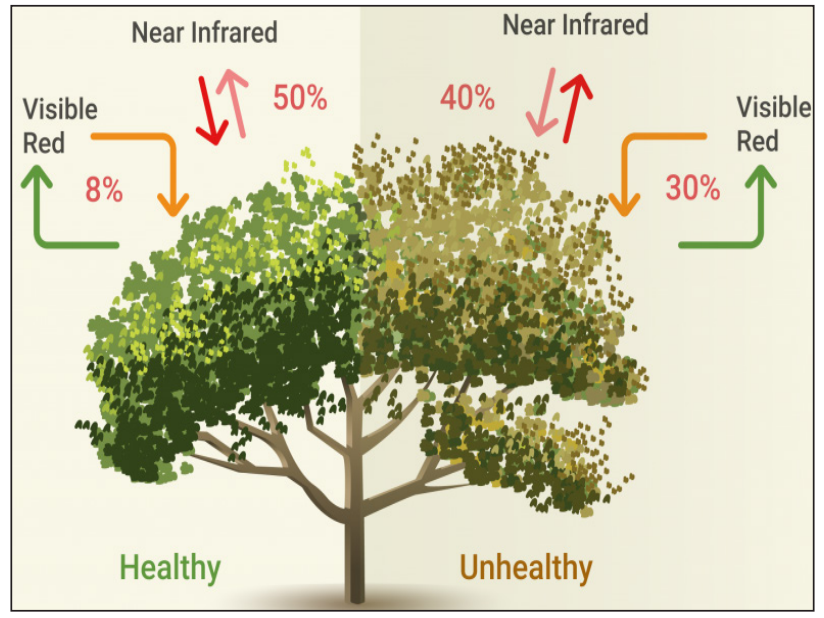

Fig. 4: NIR and RED percentages of healthy and unhealthy crops

\section{Sensor-based approach}

The sensor-based system utilizes sensors to assess crop or field conditions to provide real-time VRA of inputs. NDVI is a commonly used remote sensing technique to help identify vegetation and to provide a measure of its health and vitality. NDVI is a commonly used remote sensing technique to help identify vegetation and to provide a measure of its health and vitality. NDVI is calculated from the plant's unique reflection combination of visible red light and NIR light. It combines the information available in red and near IR bands into a single representative value given by;

$$
\mathrm{NDVI}=\frac{N I R-R E D}{N I R+R E D}
$$

NDVI value always lies between $-1 \&+1$

The application system mainly includes four parts:

- Crop nutrition monitoring system based on optical sensor;

- Interface module;

- Variable fertilization controller; and

- Variable fertilizer applicator.

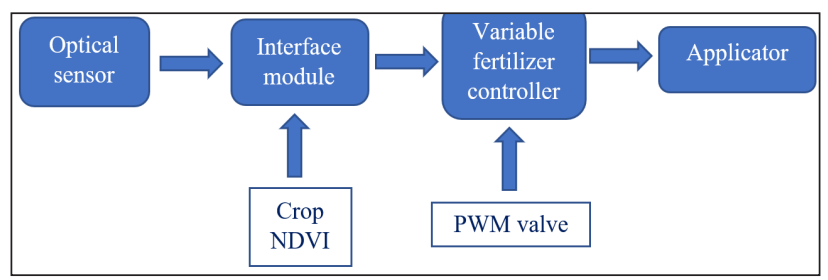

Fig. 5: Process flow of VRFS

The sensor based approach provides the capability to vary the application rate of crop production inputs with no mapping involved. The sensorbased method utilizes sensors to measure the desired properties, usually soil properties or crop characteristics, on the go. Measurements made by such a system are then processed and used immediately to control a variable rate applicator. This method doesn't necessarily require the use of a DGPS system. Nor does it require extensive data analysis prior to making variable-rate applications.

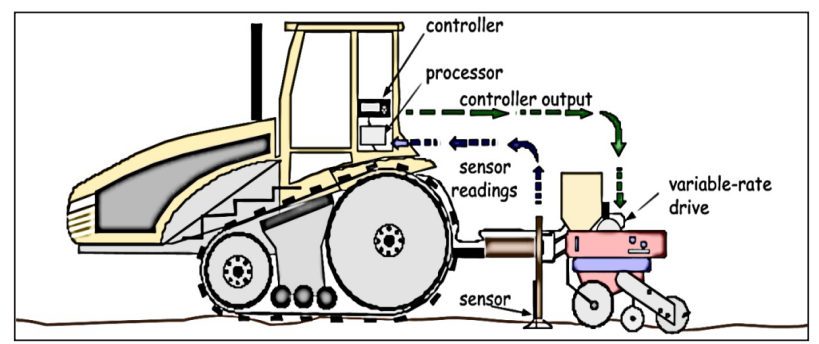

Fig. 6: A sensor-based system for varying crop input application rates 


\section{Advantages of Sensor-Based Variable Rate Application}

1. Pre-application data analysis time requirements can be eliminated.

2. Sensors produce far higher data resolution than traditional sampling methods.

3. No time delay between measurement and application with real-time systems.

4. Systems are self-contained.

Alameen et al. (2019) developed and evaluated a control system for variable rate granular fertilizer applicator. The developed VRA system was basically composed of two main units. These two units were the fertilizer flow rate control unit and the mapbased control unit. The fertilizer flow rate control unit's main responsibility was to control the flow rate by adjusting the lever. The double acting pneumatic cylinder was attached to the handle of the lever to facilitate the movement of the lever either forward or backward based on the desired fertilizer application rate. The variable rate control unit consists a microcontroller (Arduino MEGA 2560) uploaded with a developed program code was utilized to integrate the functions of the developed system components. Automatic adjustment of the desired granular fertilizer application rate was achieved successfully. The developed system can be used efficiently for VRA of granular fertilizers with an overall error of $\pm 2.6 \%$. The response time of the developed control system to adjust to a higher fertilizer application rate was $0.0062 \mathrm{~s} \mathrm{~kg}^{-1}$. However, the response time was calculated at 0.0110 $\mathrm{s} \mathrm{kg}^{-1}$ when adjusting to a lower application rate.

Zhang et al. (2013) developed a variable rate fertilizer system based on an optical sensor to control the fertilizer amount by optical sensor measured NDVI of the crop. The study analyzed the input and output conditions of a control system, designed a hardware, algorithm, and control system for fertilizer, mainly software flow, and a feedback control way. It consisted of 6 optical sensors mounted on a boom, interface module, microcontroller, speed sensor, rotation sensor, PWM valve, and hydraulic motor. It relies on sensors to provide real-time crop detection information, which is used to dispense fertilizer amounts for the crop need. A cv ranging from $0.35 \%$ to $2.67 \%$ with a maximum relative error of $5.17 \%$ was observed.
The fertilizer response time of the controller system was less than $0.875 \mathrm{~s}$.

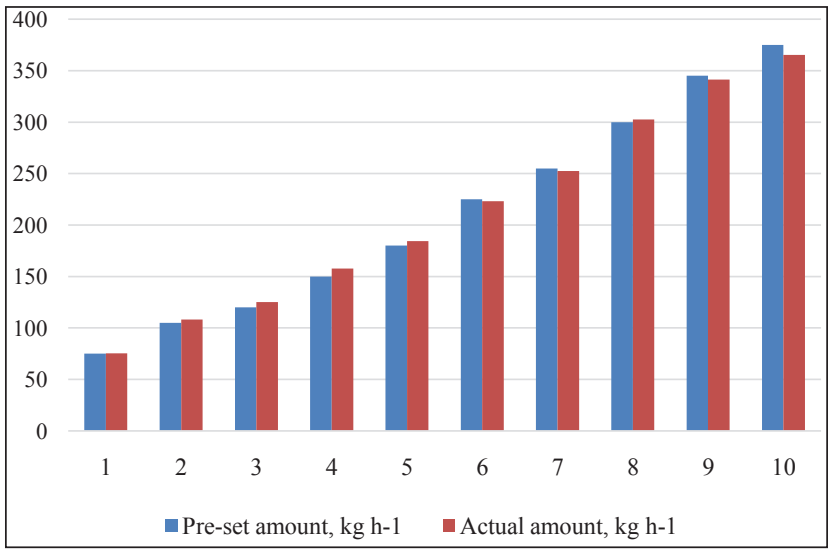

Fig. 7: Pre-set and actual fertilizer application rates at random plots

Chattha et al. (2014) modified variable rate (VR) fertilizer spreader to control each pair of nozzles for spot application of fertilizer in the blueberry field. The system consisted of cameras, solenoid valves, pneumatic cylinders, VR controllers and custom software. The modified system was capable of using prescription maps and automated sensing and control system, which simultaneously detect foliage/bare spots in real-time to avoid fertilization in bare spots/weed patches. The $\mu$ eye cameras and controller were tested and calibrated for target detection and fertilizer application. The ACCURATE controller performed reliably and efficiently to control the fertilizer application rate through each pair of nozzles with $5 \%$ difference from manual measurements. The results of response time revealed that the maximum of $2.38 \mathrm{~s}$ and 2.25 $\mathrm{s}$ were taken to dispense clay filler and fertilizer, respectively.

\section{Real time spot application using GPS}

The applicator is equipped with a long-range Radio Frequency Identification (RFID) reader to detect the stored tag ID on the available passive RFID tags attached on the trees. The Tag ID is used by the control program of the VRT system in triggering the rotary valves, which are the metering units for the system. A database containing the GPS coordinates, the RFID tag ID and the amount of fertilizer to be applied on a specified area has to be developed earlier and stored in the memory of computer system of the VRT applicator. When the 
control program receives the RFID tag ID on the tree, it relates the tag ID to the information in the database and triggers the VRT fertilizer applicator system to apply a precise amount of fertilizer to that particular area.

Ishola et al. (2013) developed a RFID-based variable rate technology fertilizer applicator for tree crops. The applicator consisted of a long-range Radio Frequency Identification (RFID) reader to detect the stored tag ID on the available passive RFID tags attached on the trees. The Tag ID was used by the control program of the VRT system in triggering the rotary valves which are the metering units for the system. The control program receives the RFID tag ID on the tree, it relates the tag ID to the information in the database and triggers the VRT fertilizer applicator system to apply precise amount of fertilizer to that particular area. The results showed that the response time of the VRT applicator was found to take $2-3$ seconds. It has a field capacity of $7.60 \mathrm{ha} / \mathrm{h}$ and $8.10 \mathrm{ha} / \mathrm{h}$ with field efficiencies of 0.55 and 0.57 at the travelling speed of $4.43 \mathrm{~km} / \mathrm{h}$ and $4.92 \mathrm{~km} / \mathrm{h}$, respectively.

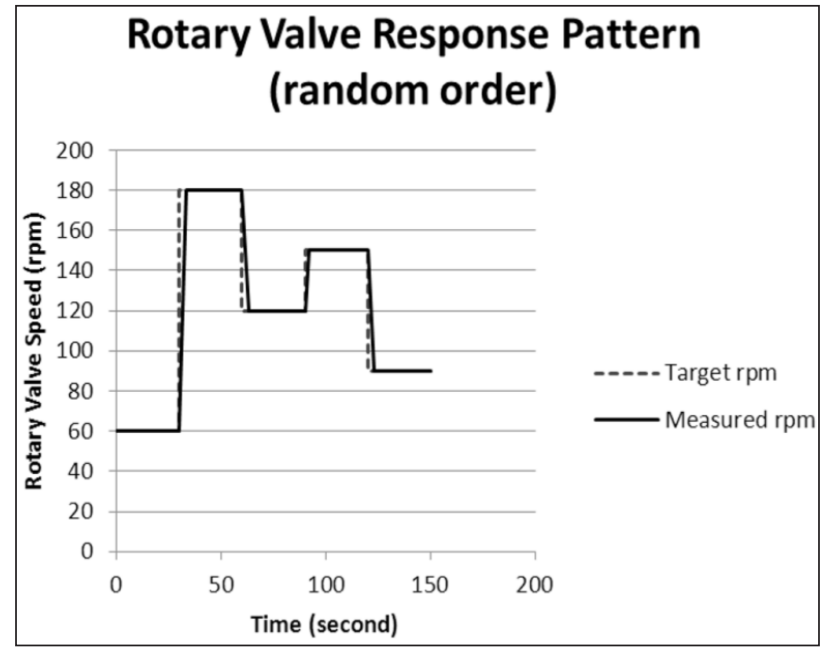

Fig. 8: Speed change of the rotary valve in random order

\section{CONCLUSION}

Variable rate fertilizer application, in this respect, is a promising technology through which:

- Crop yields, field performance, and operating productivity in agricultural operations could be maximized;

- Performance of various fertilizers and chemicals in the soils could be measured;
- Fertilizer, chemical application costs could be reduced;

- Pollution through poor use of chemicals could be reduced;

- Field performance to the square meter could be tracked, mapped, and analyzed so that to allow a farmer to be able to know how well or poorly each part of a field is producing;

- Decision-making process in farm-management could be improved;

- Better farm records essential for sale and successions could be provided.

\section{REFERENCES}

Alameen, A.A., Al-Gaadi, K.A. and Tola, E. 2019. Development and performance evaluation of a control system for variable rate granular fertilizer application. Comput. Electron. Agric., 160: 31-39.

Aware, V.V. and Aware, S.V. 2014. Development of microprocessor based electronic metering mechanism for seed - an approach. Engg. \& Tech. India, 5(1\&2): 26-31.

Barreiro, P. and Ruiz-Altisent, M. 2002. Innovative Biomechatronics aspects of mechanization, pp. 51-53.

Benji, S. 2015. Innovative Agricultural Mechatronics [Online]. Available: http://courseofthefuture.com.au/contest/1/ entry/255

Braunack, M.V. 1986. The residual effects of tracked vehicles on soil surface properties. J. Terramechanics, 23(1): 37-50.

Chandel, N.S., Mehta, C.R., Tewari, V.K. and Nare, B. 2016. Digital map-based site-specific granular fertilizer application system. Curr. Sci., 111(7): 1208-1213.

Chattha, H.S., Zaman, Q.U., Chang, Y.K., Read, S., Schumann, A.W., Brewster, G.R. and Farooqu, A.A. 2014. Variable rate spreader for real-time spot-application of granular fertilizer in wild blueberry. Comput. Electron Agric., 100: 70-78.

Erdélyi and Jánosi. 2017. Mechatronics in Agriculture, Scientific Bulletin, Serie C, Fascicle: Mechanics, Tribology, Mach. Manuf. Technol., ISSN 1224-3264.

Forouzanmehr, E. and Loghavi, M. 2012. Design, development and field evaluation of a map-based variable rate granular fertilizer application control system. Int. J. Aric. Eng., 14(4): 255- 261.

Hamid, A., Ahmad, D. and Rukunuddin, I.H. 2010. Performance of sweet potato transplanting machine on mineral and bris soils. Agric. Mechanization in Asia, Afr. and Latin Am., 41(1):55-59.

Ishak and Hudzari, R.M. 2010. Image Based modeling for oil palm fruit maturity prediction. Jr. Food, Agric. Env., 8(2): 469-476.

Jaime Cuauhtemoc Negrete. 2015. Mechatronics in Mexican Agriculture Current Status and Perspectives. Int. J. Agric. $\mathcal{E}$ Environ. Sci., 2(3). 
Kim, Y.J., Kim, H.J., Rye, K.H. and Rhee, J.Y. 2008. Fertilizer application performance of a variable-rate pneumatic granular applicator for rice production. Biosyst. Eng., 100: 498-510.

Mohd Ekhwan Hj Toriman, Mazlin B. Mokhtar, Muhammad Barzani Gazim, Norazlina Abd Aziz. 2009. Analysis of the Physical Characteristics of BRIS soil. Res. J. Earth Sci., pp. 1-2.

Mouazen, A.M., Karoui, R., Decksers, J., De Baerdemaeker, J. and Ramon, H. 2007. Potential of visible and near-infrared spectroscopy to derive colour groups utilising the Munsell soil colour charts. Biosyst. Eng., 97(2): 131-143.

Prem Veer Gautam, H.L. Kushwaha, Adarsh Kumar and Kushwaha, D.K. 2019. Mechatronics Application in Precision Sowing. Int. J. Curr. Microbiol. App. Sci., 8(4): 1793-1807.

Razali M.H., Wan Ismail W.I., Ramli A.R. and Sulaiman M.N. 2008. Modeling of Oil Palm Fruit Maturity for the Development of an Outdoor Vision System. Int. J. Food Eng., 4(3): 1396-1396.

Razali, M.H.H., Noor, N.A.M., Othman, N.I. and Hamdan, H.I. 2012. Mechatronic application for agriculture mechanization analysis and education. Software Eng., 2(4): 106-111.

Rooney, D., Stelford, M. and Landolt, D. Undated. SiteSpecific Soil Compaction Mapping Using a Digital Soil Penetrometer. Site-Specific Management Guidelines (SSMG) Potash and Phosphate Institute (http://www. ppi-far.org/ssmg).
Rui Zhang, Xiu Wang, Jianhua Guo, Liping Chen, Jianjun Zhou and Wei Ma. 2014. Development of Variable Rate Fertilizer System Based on Optical Sensor. Sens. Transducers, 26: 1-6.

Sebastian, S. 2014. Laboratory tests of force sensor applied in agricultural mechatronic equipment. Teka. Commission of Motorization and Energetic Agric., 14(3): 111-114.

Shankha Koley, Y.C. Bhatt, Gajendra Singh, Sunil Joshi and Jain, H.K. 2017. Development of Electronic Metering Mechanism for Precision Planting of Seeds Int. J. Curr. Microbiol. App. Sci., 6(8): 3481-3487.

Sinder, K.O. and Tekin, A.B. 2002. Economics of variable rate fertilizer application. International Scientific Conference, Rousse, Bulgaria.

Su Ning, Xu Taosheng, Song Liangtu, Wang Rujing and Wei Yuanyuan. 2015. Variable rate fertilization system with adjustable active feed-roll length. Int. J. Agric. Bio Eng., 8(4): 19-26.

Tola, E., Kataoka, T., Burce, M., Okamoto, H. and Hata, S. 2008. Granular fertilizer application rate control system with integrated output volume measurement. Biosyst. Eng., 101(4): 411-416.

Yang, L., Xiantao, H., Tao, C., Dongxing, Z., Song, S., Rui, Z. and Mantao, W. 2012. Development of the mechatronic driving system for seed meters equipped on conventional precision corn planter, Int. J. Agric. Biol. Engg., 8(4): 1-9. 
